\title{
TITAN2F: a pseudo-3-D model of 2-phase debris flows
}

\section{G. Córdoba ${ }^{1}$, M. F. Sheridan ${ }^{2}$, and E. B. Pitman ${ }^{3}$}

${ }^{1}$ Universidad de Nariño, Pasto, Colombia

${ }^{2}$ Center for Geohazards Studies and Department of Geology, University of Buffalo, Buffalo, NY 14260, USA

${ }^{3}$ Center for Geohazards Studies and Department of Mathematics, University of Buffalo, Buffalo, NY 14260, USA

Received: 15 January 2015 - Accepted: 22 April 2015 - Published: 12 June 2015

Correspondence to: G. Córdoba (gcordobaguerrero@gmail.com)

Published by Copernicus Publications on behalf of the European Geosciences Union.

A model for two phase debris flows

G. Córdoba et al.

Title Page

Abstract

Introduction

Conclusions

References

Tables

Figures

14

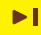

4

Back

Close

Full Screen / Esc

Printer-friendly Version

Interactive Discussion 


\section{Abstract}

Debris flows, avalanches, landslides, and other geophysical mass flows can contain $O\left(10^{6}-10^{10}\right) \mathrm{m}^{3}$ or more of material. These flows commonly consist of mixture of soil and rocks with a significant quantity of interstitial fluid. They can be tens of meters 5 deep, and their runouts can extend many kilometers. The complicated rheology of such a mixture challenges every constitutive model that can reasonably be applied; the range of length and timescales involved in such mass flows challenges the computational capabilities of existing systems. This paper extends recent efforts to develop a depth averaged "thin layer" model for geophysical mass flows that contain a mixture of solid material and fluid. Concepts from the engineering community are integrated with phenomenological findings in geo-science, resulting in a theory that accounts for the principal solid and fluid forces as well as interactions between the phases, across a wide range of solid volume fraction. A principal contribution here is to present drag and phase interaction terms that comport with the literature in geo-sciences. The program 15 predicts the evolution of the concentration and dynamic pressure. The theory is validated with with data from one dimensional dam break solutions and it is verified with data from artificial channel experiments.

\section{Introduction}

Globally there are about 50 volcanoes that erupt every year. During the past century tens of thousands of people have been killed by volcanic flows and hundreds of thousands forced from their homes (Tilling, 1996; The-Committee-on-Natural-Disasters, 1991; U.S.-Geodynamics-Committee, 1994). Two-phase mass flows containing water and solid particles, called lahars, are common in volcanic regions. They can be initiated by several mechanisms. A volcanic explosion can be accompanied by large plumes and at speeds as high as $100 \mathrm{~m}$ per second (Sheridan, 1979). The hot ash can melt snow,

NHESSD

3, 3789-3822, 2015

A model for two phase debris flows

G. Córdoba et al.

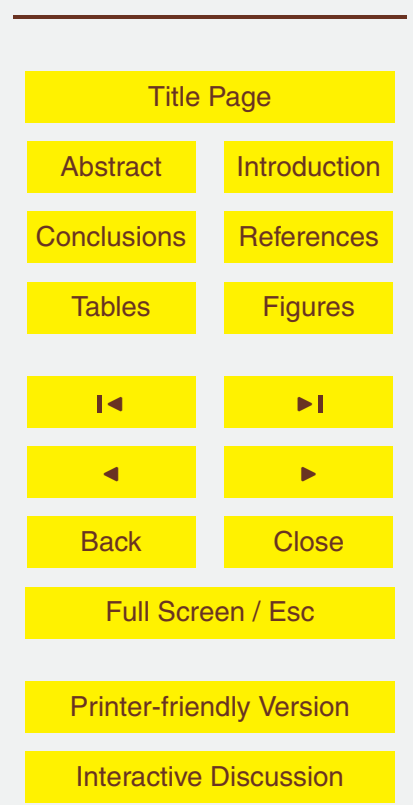

Interactive Discussion 
creating a muddy mixture that knock down trees and entrain rocks and boulders into the flow. Cotopaxi Volcano in Ecuador is an example of a volcano that has produced many large lahars by this process in the past (Pistolesi et al., 2013). Crater lakes on volcanoes are another source of mud flows, a recent example being the 2007 lahar of 5 Ruapehu in New Zealand (Procter et al., 2010). A third mechanism for initiating lahars is intense rainfall on hillsides that are devoid of vegetation and exposures of loose material like clay soils or volcanic ash. An example of this type of lahar is the 1998 mudflow at Casita Volcano in Nicaragua that occurred during Hurricane Mitch and caused hundreds of deaths (Sheridan et al., 1999). Lahars can carry constituent particles that are ypically from clay to boulder size and can propagate tens of kilometers before coming to rest (Procter et al., 2010). As solid particle sediment out of the flowing mass the resulting deposits can be up to one hundred meters thick (Legros, 2002). However, the typical deposits left after a debris flow passes are on the scale of meters.

In order to develop a complete mathematical model of mud and debris flows, two 15

principal challenges must be overcome: rheology, and scale. First, constitutive relations must be developed to describe granular material including clays, sands, pebbles and rocks, with interstitial water. Second, a computational method must be developed that extends over six orders of magnitude. Neither of these challenges can be fully met at this time. This paper tries to strike a balance between fidelity to the physics of mass flows and computational feasibility. We describe a modeling effort that draws on the wisdom from engineering and geo-science, to postulate constitutive theory and fluidsolid interaction effects, and, through a depth averaging process, results in a system of equations that is computationally tractable.

The modeling effort here has its origins the pioneering work of Savage and Hutter 25 (Savage and Hutter, 1989). They began with mass and momentum balance laws based on a Coulomb constitutive description of dry granular material. By scaling and depth averaging, they develop a "thin layer" model for granular flows down inclines. Flow over general topography was addressed in Gray et al. (1999), Patra et al. (2005), and Pudasaini and Hutter (2003). Comparison of thin layer model results to historic flows

\section{NHESSD}

3, 3789-3822, 2015

\section{A model for two phase debris flows}

G. Córdoba et al.

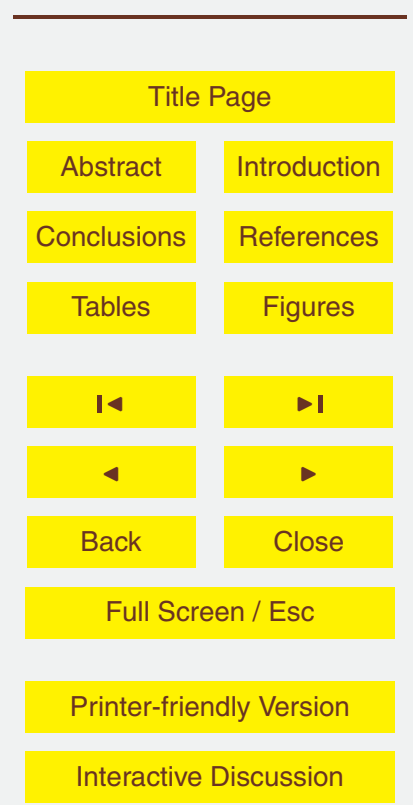

3791 
is presented in Sheridan et al. (2005). In Hutter et al. (2003), the appropriateness of these thin layer models is considered, for several different types of geophysical flows. Much of the modeling effort is summarized in Pudasaini and Hutter (2007).

Iverson and his co-workers (Iverson, 1997; Iverson and Denlinger, 2001) argue that 5 the presence of interstitial fluid fundamentally alters the behavior of geophysical flows, and fluid effects should be included in the constitutive behavior of the flowing material. Starting with equations of mixture theory (Bedford and Drumheller, 1983) and through a careful examination of experiments, these papers developed a system of mass and momentum balance laws for the mixture. Unfortunately in this development an equation 10 for the motion of pore fluid was not readily available. Instead, based on experimental data, a transport equation for the fluid was postulated.

A different approach, based on a fully three-dimensional model of two phase flows, can be found in Meruane et al. (2010) and Dartevelle (2004).

Pitman and Le (Pitman and Le, 2005) rigorously developed a two phase thin layer 15 model of fluid and granular material. They begin with a fully three dimensional model of two phase flows, based on model equations in engineering (Jackson, 2000). The model equations are scaled and depth averaged. The resulting system of equations is not complete, and closure assumptions are required. With these assumptions, the mathematical system is shown to be hyperbolic under common conditions, and thus well posed (see Pelanti et al., 2008). The model of Pitman and Le (2005) includes a drag term, which is the only term describing the interaction of the two phases; the coefficient of drag must be fitted to experiments. That model assumes the fluid is inviscid, and that there is no frictional dissipation in the fluid phase at the basal surface. Both of these features, which are reasonable in bench-scale fluidized bed experiments, are suspect for large mass flows. This paper reconsiders the model equations of Pitman and Le (2005) and proposes a revision that better represents two phase geophysical flows. Related work can be found in Valentine and Wohletz (1989) and Dobran (1991). A different approach to modeling mud flows employ a visco-plastic constitutive assumptions (Mei at al, 2001; Coussot, 1997); see also Ancey (2006) and Balmforth and
NHESSD

3, 3789-3822, 2015

A model for two phase debris flows

G. Córdoba et al.

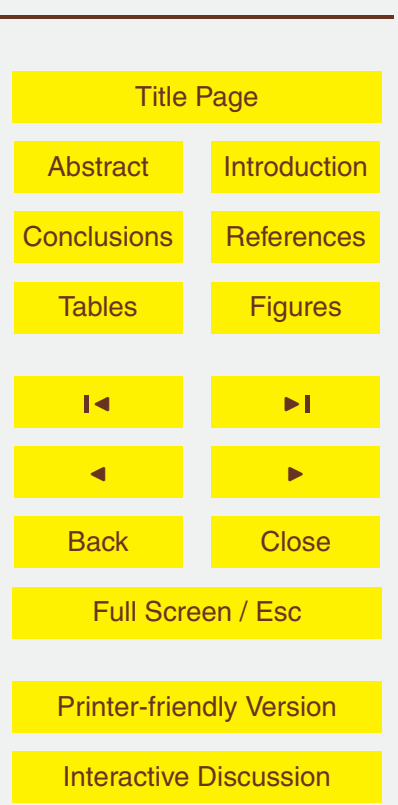

3792 
Craster (1999). In these papers, the choice of visco-plastic flow model drives the subsequent derivation, as well as the required parameter-fitting necessary for the constitutive relations. The process of depth averaging a visco-plastic flow is always difficult. The interface between yielding and non-yielding material is itself a free surface that must be 5 determined. This attribute requires the use of multiple layers in the model system, with all the resulting complexity.

\section{Model derivation}

This paper uses a similar framework to that developed in Pitman and Le (2005). However, a complete set of model equations for a granular phase and for a fluid phase are 1 written. Phase interaction terms are modeled, and scaling of all terms suggests simplifications that can be made. Depth averaging and closure assumptions completes the derivation.

A note on sign convention: in soil mechanics it is common to consider compressive stresses as positive; in fluid mechanics compression is negative. We caution the reader to observe the sign convention in the equations below.

\subsection{Fundamental assumptions}

The fundamental theory of two phase flows can be found in Dobran (1991) and Jackson (2000). In two space dimensions, consider a thin layer of granular material (s) and interstitial fluid (f), each of constant specific density $\rho^{\mathrm{s}}$ and $\rho^{f}$, respectively, flowing over a smooth basal surface, $b$. Neglect any erosion. Along the basal surface, define a Cartesian coordinate system $O x y z$, with origin $O$ defined so the $O x y$ is tangent to the basal surface, with the $x$ direction the downstream direction, and $O z$ is in the normal direction. Write $\boldsymbol{v}, \boldsymbol{u}$ for the velocities of the solid and fluid constitutients, respectively, and $\varphi$ for the solid volume fraction. We assume the mass is fully saturated, so the

\section{NHESSD}

3, 3789-3822, 2015

A model for two phase debris flows

G. Córdoba et al.

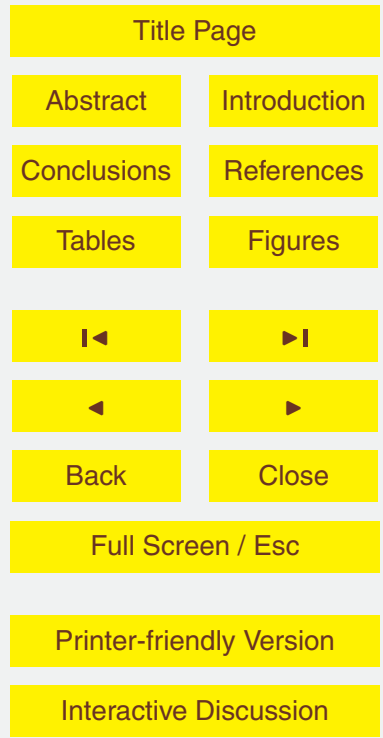


component form, we use subscripts to denote the component, and superscripts the phase.

Mass conservation for the two constitutent phases may be written as in Anderson and Jackson (1967):

${ }_{5} \partial_{t} \rho^{\mathrm{s}} \varphi+\nabla \cdot\left(\rho^{\mathrm{s}} \varphi v_{i}\right)=0$

$\partial_{t} \rho^{f}(1-\varphi)+\nabla \cdot\left(\rho^{f}(1-\varphi) u_{i}\right)=0$

The momentum equations are:

$\partial_{t}\left(\rho^{\mathrm{s}} \varphi \boldsymbol{v}\right)+\nabla \cdot\left(\rho^{\mathrm{s}} \varphi \boldsymbol{v} \boldsymbol{v}\right)=\nabla \cdot T^{\mathrm{s}}+f^{\mathrm{s}}+\rho^{\mathrm{s}} \varphi \boldsymbol{g}$

$\partial_{t}\left(\rho^{f}(1-\varphi) \boldsymbol{u}\right)+\nabla \cdot\left(\rho^{\mathrm{f}}(1-\varphi) \boldsymbol{u} \boldsymbol{u}=\nabla \cdot T^{\mathrm{f}}+f^{\mathrm{f}}+\rho^{\mathrm{f}}(1-\varphi) \boldsymbol{g}\right.$

10 Here $T^{\mathrm{s}}, T^{\mathrm{f}}$ are the stress tensors for the solid and fluid, and $f^{\mathrm{s}}, f^{\mathrm{f}}$ the interaction force between the phases. We must postulate constitutive relations and an equation for the interphase force, to close the system. Jackson (2000) presents an argument for separating buoyancy from other interphase force terms (such as drag or virtual mass), and for properly accounting for buoyancy in a field with fluid pressure variations. Similar 5 modeling can be found in Neri et al. (2003), Neri et al. (2007), Dobran (2001), Dobran et al. (1993) and Valentine and Wohletz (1989). Neglecting capillarity, virtual mass and lift, we postulate

$f^{\mathrm{s}}=-\varphi \nabla T^{\mathrm{f}}+D(\boldsymbol{v}-\boldsymbol{u})$

$f^{\dagger}=-f^{s}$

20 Here the total fluid stress is $T^{f}=-P^{f}+\tau^{f}$, where $P^{f}$ is the fluid pressure and $\tau^{f}$ is the viscous contribution to the fluid stress. The drag term exchanges momentum between the phases, with a coefficient $D$ that is phenomenological; Wallis (1969), Ergun (1952), Gidaspow (1994), Fan and Zhu (1998), Dobran (2001), Panneerselvan et al. (2007), and Mazzei and Lettieri (2007) among other sources, suggest values. As $\varphi \rightarrow 1$ the 3794
NHESSD

3, 3789-3822, 2015

A model for two phase debris flows

G. Córdoba et al.

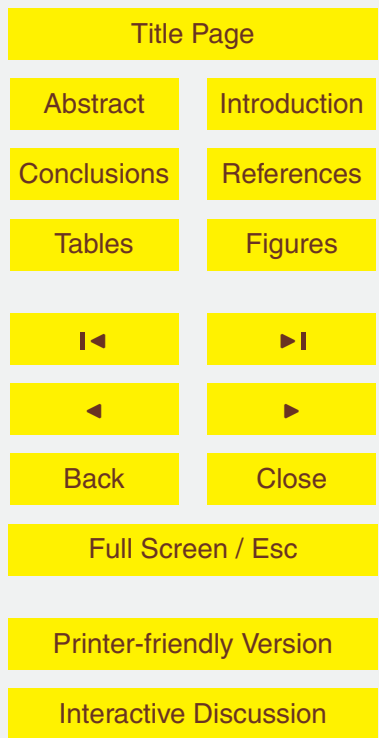

Interactive Discussion 
effect of fluid forces becomes less important, relative to frictional forces. When $\varphi \rightarrow 0$, the drag vanishes. Following Mazzei and Lettieri (2007), we set

NHESSD

$D=\frac{3}{4} C_{\mathrm{d}} \frac{\rho^{\mathrm{f}} \varphi|\boldsymbol{v}-\boldsymbol{u}|}{d}(1-\varphi)^{-\alpha}$

where $d$ is the mean particle diameter, $\alpha$ is a constant related to the constant $n$ in 5 Ricardson-Zaki equation (Khan and Richardson, 1989). According to Mazzei and Lettieri (2007), this constant equals 2.80 either when $R_{e_{p}} \rightarrow 0$ or $R_{e_{p}} \rightarrow \infty$, thus we use $\alpha=2.80$ in Eq. (6). Finally, he drag coeficient is assumed to be constant $C_{\mathrm{d}}=1$.

\subsection{Scaling}

The characteristic thickness of the flowing granular material is $H$ and the character-

10 istic length $L$. Scale $x$ and $y$ by $L$, and $z$ by $H$, time by the free fall time $\sqrt{L / g}$, and the $x, y$ and $z$ velocities by $\sqrt{L g}$ and $\frac{H}{L} \sqrt{L g}$, respectively. All stresses are scaled by $\rho^{\mathrm{s}} \mathrm{gH}$. After scaling the mass balance equations are unchanged. Several terms in the momentum equations contain the factor $\epsilon=H / L$ which is small; $\epsilon \approx 0.01-0.001$ is not uncommon (Iverson and Denlinger, 2001). Writing $x, y, z$ for $x_{1}, x_{2}, x_{3}$, the solid
3, 3789-3822, 2015

A model for two phase debris flows

G. Córdoba et al.

Title Page

Abstract

Introduction

Conclusions

References

Tables

Figures

14

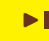

4

Back

Close

Full Screen / Esc

Printer-friendly Version

Interactive Discussion 
momentum balance equations become

$\partial_{t}\left(\varphi v_{x}\right)+\partial_{x}\left(\varphi v_{x} v_{x}\right)+\partial_{y}\left(\varphi v_{y} v_{x}\right)+\partial_{z}\left(\varphi v_{z} v_{x}\right)$

NHESSD

$=\partial_{x} \epsilon T_{x x}^{\mathrm{s}}+\partial_{y} \epsilon T_{x y}^{\mathrm{s}}+\partial_{z} T_{x z}^{\mathrm{s}}-\epsilon \frac{\rho^{\mathrm{f}}}{\rho^{\mathrm{s}}} \varphi \partial_{x} T_{x x}^{\mathrm{f}}$

$-\epsilon \frac{\rho^{\mathrm{f}}}{\rho^{\mathrm{s}}} \varphi \partial_{y} T_{x y}^{\mathrm{f}}-\frac{\rho^{\mathrm{f}}}{\rho^{\mathrm{s}}} \varphi \partial_{z} T_{x z}^{\mathrm{f}}+\frac{D}{\rho^{\mathrm{s}}}\left(v_{x}-u_{x}\right)+\varphi g_{x}$

${ }_{5} \partial_{t}\left(\varphi v_{y}\right)+\partial_{x}\left(\varphi v_{x} v_{y}\right)+\partial_{y}\left(\varphi v_{y} v_{y}\right)+\partial_{z}\left(\varphi v_{z} v_{y}\right)$

$=\partial_{x} \epsilon T_{x y}^{\mathrm{s}}+\partial_{y} \epsilon T_{y y}^{\mathrm{s}}+\partial_{z} T_{y z}^{\mathrm{s}}-\epsilon \frac{\rho^{\mathrm{f}}}{\rho^{\mathrm{s}}} \varphi \partial_{x} T_{x y}^{\mathrm{f}}$

$-\epsilon \frac{\rho^{\mathrm{f}}}{\rho^{\mathrm{s}}} \varphi \partial_{y} T_{y y}^{\mathrm{f}}-\frac{\rho^{\mathrm{f}}}{\rho^{\mathrm{s}}} \varphi \partial_{z} T_{y z}^{\mathrm{f}}+\frac{D}{\rho^{\mathrm{s}}}\left(v_{y}-u_{y}\right)+\varphi g_{y}$

$\epsilon\left(\partial_{t}\left(\varphi v_{z}\right)+\partial_{x}\left(\varphi v_{x} v_{z}\right)+\partial_{y}\left(\varphi v_{y} v_{z}\right)+\partial_{z}\left(\varphi v_{z} v_{z}\right)\right)$

$=\partial_{x} \epsilon T_{x z}^{\mathrm{s}}+\partial_{y} \epsilon T_{y z}^{\mathrm{s}}+\partial_{z} T_{z z}^{\mathrm{s}}-\epsilon \frac{\rho^{\mathrm{f}}}{\rho^{\mathrm{s}}} \varphi \partial_{x} T_{x z}^{\mathrm{f}}$

$-\epsilon \frac{\rho^{\mathrm{f}}}{\rho^{\mathrm{s}}} \varphi \partial_{y} T_{y z}^{\mathrm{f}}-\frac{\rho^{\mathrm{f}}}{\rho^{\mathrm{s}}} \varphi \partial_{z} T_{z z}^{\mathrm{f}}+\epsilon \frac{D}{\rho^{\mathrm{s}}}\left(v_{z}-u_{z}\right)+\varphi g_{z}$

Note that components of gravity have been scaled by the magnitude $|g|$, so $\left(g_{x}, g_{y}, g_{z}\right)$ is a unit vector.

3, 3789-3822, 2015

A model for two phase debris flows

G. Córdoba et al.

Title Page

Abstract

Introduction

Conclusions

References

Tables

Figures

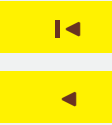

Back

Close

Full Screen / Esc

Printer-friendly Version

Interactive Discussion 


$$
\begin{aligned}
& \partial_{t}\left((1-\varphi) u_{x}\right)+\partial_{x}\left((1-\varphi) u_{x} u_{x}\right)+\partial_{y}\left((1-\varphi) u_{y} u_{x}\right)+\partial_{z}\left((1-\varphi) u_{z} u_{x}\right) \\
& =\partial_{x} \epsilon(1-\varphi) T_{x x}^{f}+\partial_{y} \epsilon(1-\varphi) T_{x y}^{f}+\partial_{z}(1-\varphi) T_{x z}^{f}-\frac{D}{\rho^{f}}\left(v_{x}-u_{x}\right)+(1-\varphi) g_{x} \\
& \partial_{t}\left((1-\varphi) u_{y}\right)+\partial_{x}\left((1-\varphi) u_{x} u_{y}\right)+\partial_{y}\left((1-\varphi) u_{y} u_{y}\right)+\partial_{z}\left((1-\varphi) u_{z} u_{y}\right) \\
& =\partial_{x} \epsilon(1-\varphi) T_{x y}^{f}+\partial_{y} \epsilon(1-\varphi) T_{y y}^{f}+\partial_{z}(1-\varphi) T_{y z}^{f}-\frac{D}{\rho^{f}}\left(v_{y}-u_{y}\right)+(1-\varphi) g_{y} \\
& \epsilon\left(\partial_{t}\left((1-\varphi) u_{z}\right)+\partial_{x}\left((1-\varphi) u_{x} u_{z}\right)+\partial_{y}\left((1-\varphi) u_{y} u_{z}\right)+\partial_{z}\left((1-\varphi) u_{z} u_{z}\right)\right) \\
& =\partial_{x} \epsilon(1-\varphi) T_{x z}^{f}+\partial_{y} \epsilon(1-\varphi) T_{y z}^{f}+\partial_{z}(1-\varphi) T_{z z}^{f}-\epsilon \frac{D}{\rho^{f}}\left(v_{z}-u_{z}\right)+(1-\varphi) g_{z}
\end{aligned}
$$

In summary, then, the proposed equation system consists of the solid volume fraction $\varphi$, the three solid velocities $\boldsymbol{v}$, and three fluid velocities $\boldsymbol{u}$. These variables evolve ac10 cording to the six momentum balance laws for the species, and the mass conservation relations for each species.

\subsection{Constitutive assumptions and boundary conditions}

The upper surface of the flowing mass at $F_{h}(x, y, t)=0$ is assumed to be a material surface and stress free. At the base of the mass, material is assumed to flow tangent 15 to the basal surface $F_{\mathrm{b}}=0$, and to satisfy a sliding friction law. For the solid constituent, this friction relation specifies that the shear traction and the normal stress are proportional: $\left.S\right|_{F_{\mathrm{b}}}=-\left.\operatorname{sgn}(v) N\right|_{F_{\mathrm{b}}} \tan \left(\phi_{\text {bed }}\right)$, where $\phi_{\text {bed }}$ is the basal friction angle and the $-\operatorname{sgn}(v)$ specifies that the shear traction opposes motion. For the fluid, the basal stress condition will be addressed below.

We now discuss constitutive relations. A Coulomb constitutive relation is postulated for the material. The Coulomb law is a nonlinear relation among the components of $\mathbf{T}^{\mathrm{s}}$, and stipulated that material deforms when the total stress reaches yield,

\section{NHESSD}

3, 3789-3822, 2015

A model for two phase debris flows

G. Córdoba et al.

Title Page

Abstract

Introduction

Conclusions

References

Tables

Figures

14

$>$ I

4

Back

Close

Full Screen / Esc

Printer-friendly Version

Interactive Discussion 
$\left\|\operatorname{dev}\left(\mathbf{T}^{\mathrm{s}}\right)\right\|=\kappa \operatorname{tr}\left(\mathbf{T}^{\mathrm{s}}\right)$, where $\operatorname{dev}\left(\mathbf{T}^{\mathrm{s}}\right)=\mathbf{T}^{\mathrm{s}}-\frac{1}{2} \operatorname{tr}\left(\mathbf{T}^{\mathrm{s}}\right) \mathbf{I}$ is the stress deviator, $\operatorname{tr}\left(\mathbf{T}^{\mathrm{s}}\right)$ is the trace of the stress (the sum of the diagonal components), $\mathbf{I}$ is the identity tensor, and $k$ is a material parameter, and that as deformation occurs, the stress and strain-rate tensors are aligned. That is, the alignment condition specifies $\operatorname{dev}\left(\mathbf{T}^{s}\right)=\lambda \operatorname{dev}(\mathbf{V})$, where 5 the strain-rate $\mathbf{V}=-\frac{1}{2}\left(\nabla \boldsymbol{v}+\nabla \boldsymbol{v}^{\dagger}\right)$ and $\dagger$ denotes the transpose. To avoid a switching between plastic and non-plastic behavior, we assume the solid material is everywhere in plastic yield.

The full Coulomb relations are too complex to be used here. Two simplifications are proposed. First, at the basal surface the boundary condition ensures proportionality 10 and alignment of the tangential and normal forces; we assume the same proportionality and alignment holds throughout the thin flowing layer of material. Written in components this implies $T_{\mathrm{ab}}{ }^{\mathrm{s}}=v_{\mathrm{ab}} T_{z z} \mathrm{~s}$, where the proportionality constant $v$ is a function of $\phi_{\text {bed }}$. Second, following Rankine (1957) and Terzaghi (1936), an earth pressure relation is assumed for the diagonal stress components, $T_{x x}{ }^{\mathrm{s}}=k_{\mathrm{ap}} T_{z z} \mathrm{~s}$, where

$15 \quad k_{\text {ap }}=2 \frac{1 \pm\left[1-\cos ^{2}\left(\phi_{\text {int }}\right)\left[1+\tan ^{2}\left(\phi_{\text {bed }}\right)\right]\right]^{\frac{1}{2}}}{\cos ^{2}\left(\phi_{\text {int }}\right)}-1$.

Here $\phi_{\text {int }}$ is the internal friction angle and the choice of the plus or minus sign depends on whether flow is locally expanding (the active state, with $\nabla \cdot v>0$, and the - sign) or contracting (the passive state, with $\nabla \cdot v<0$, and the + sign).

\section{Depth averaging}

20 The final step in the derivation is a depth averaging of the mass and momentum balance equations. That is, for some function $f$, we compute

$\frac{1}{|h-b|} \int_{b(x, y)}^{h(x, y, t)} f(x, y, z, t) \mathrm{d} z=\bar{f}$

\section{NHESSD}

3, 3789-3822, 2015

A model for two phase debris flows

G. Córdoba et al.

Title Page

Abstract

Introduction

Conclusions

References

Tables

Figures

14

$>$ I

4

Back

Close

Full Screen / Esc

Printer-friendly Version

Interactive Discussion 
Repeated use of the Leibnitz rule is made to interchange integration and differentiation, and boundary conditions are employed to evaluate terms at $b$ and $h$. In addition, several approximations must be made during the depth averaging process. In what follows, we only briefly sketch the depth averaging process, noting as appropriate those places 5 where approximations are made. Pitman and Le (2005) provides an estimation of the errors typically made by these assumptions.

The terms of order $\epsilon$ are assumed small and we hope to drop all such terms from the model. However Savage and Hutter (1989) argues that diagonal contributions to the solid stress must be retained. Because there is no preferential downslope direction in 10 our applications, and the flow direction may change during a flow, we retain the stress terms in both the $x$ and $y$ directions, dropping only $O(\epsilon)$ terms in the $z$ direction; see the discussion in Iverson and Denlinger (2001). Other $O(\epsilon)$ terms are dropped.

\section{Mass balance equation}

$\nabla \cdot(\varphi \boldsymbol{v}+(1-\varphi) \boldsymbol{u})=0$.

15 says that the volume-weighted mixture flow is divergence free. That the mixture is isochoric allows us to depth average:

$\int_{b}^{h} \nabla \cdot(\varphi \boldsymbol{v}+(1-\varphi) \boldsymbol{u}) \mathrm{d} z=0$.

Use the Leibniz rule to interchange differentiation and integration. The upper free surface $F_{h}=0$ is a material surface for the mixture, so at $z=h(x, y, t)$

$\partial_{t}(\varphi h+(1-\varphi) h)+\left(\varphi v_{x}+(1-\varphi) u_{x}\right) \partial_{x} h$

$+\left(\varphi v_{y}+(1-\varphi) u_{y}\right) \partial_{y} h-\left(\varphi v_{z}+(1-\varphi) u_{z}\right)=0$.

Likewise, at the basal surface $F_{\mathrm{b}}=0$ flow is tangent to the fixed bed so

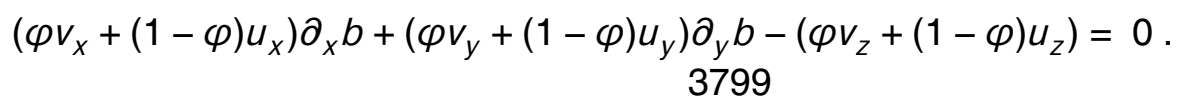

NHESSD

3, 3789-3822, 2015

A model for two phase debris flows

G. Córdoba et al.

Title Page

Abstract

Introduction

Conclusions

References

Tables

Figures

14

$>$ I

4

Back

Close

Full Screen / Esc

Printer-friendly Version

Interactive Discussion 
In arriving at these equations, we have ignored sedimentation, entrainment, and infiltration of fluid into the bed.

Using these formulae and algebraic manipulation,the depth averaged equation for the total mass of the solid and fluid can be written

${ }_{5} \partial_{t} \hat{h}+\partial_{x}\left(\hat{h}\left(\overline{\varphi v_{x}}+\overline{(1-\varphi) u_{x}}\right)\right)+\partial_{y}\left(\hat{h}\left(\overline{\varphi v_{y}}+\overline{(1-\varphi) u_{y}}\right)\right)=0$.

In writing this equation, the depth averaged velocities are $\hat{h} \overline{v_{x}}=\int_{b}^{h} v_{x} \mathrm{~d} z$, with a similar expression for the volume fraction $\bar{\varphi}$ and the other velocity components, where $\hat{h}=$ $h-b$.

\section{$z$ momentum}

10 Observe that, upon setting $\epsilon \rightarrow 0$ in the fluid $z$ momentum equation, we find the fluid to be hydrostatic:

$\partial_{z} T_{z z}^{\mathrm{f}}=g_{z}$

Integrating and imposing boundary conditions, we find

$T_{z z}^{f}(x, y, z)=-g_{z}[h-z]$,

15 and the average

$\bar{T}_{z z}^{f}(x, y)=-\frac{1}{2} g_{z} \hat{h}$.

In the same manner, for the solid $z$ momentum we find equation for an effective stress:

$\partial_{z} T_{z z}^{\mathrm{s}}+\frac{\rho^{\mathrm{f}}}{\rho^{\mathrm{s}}} \varphi \partial_{z} T_{z z}^{\mathrm{f}}=\varphi g_{z}$

NHESSD

3, 3789-3822, 2015

A model for two phase debris flows

G. Córdoba et al.

Title Page

Abstract

Introduction

Conclusions

References

Tables

Figures

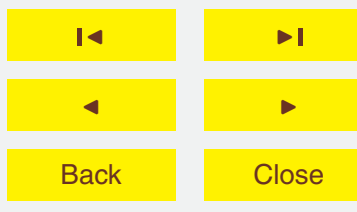

Full Screen / Esc

Printer-friendly Version

Interactive Discussion 
Substituting,

$\partial_{z} T_{z z}^{\mathrm{s}}=\left(1-\frac{\rho^{\mathrm{f}}}{\rho^{\mathrm{s}}}\right) g_{z} \varphi=\left(1-\frac{\rho^{\mathrm{f}}}{\rho^{\mathrm{s}}}\right) \varphi \partial_{z} T_{z z} f$.

NHESSD

3, 3789-3822, 2015

Thus the normal solid stress in the $z$ direction at any height is equal to the (buoyancy) reduced weight of the solid material overburden.

$5 \quad$ In scaling these equations, the $z$ velocities have been dropped. Of course neglecting motion in the $z$ direction is a central component of a thin layer theory. Furthermore, any contribution to the $z$ momentum from fluid shearing - terms such a $T_{x z}^{f}, T_{y z}^{f}$ - are dropped due to scaling. This observation suggests that only pressure contributions to the fluid stress are important, an assumption we will make below, albiet with a modification at the basal surface.

\section{$x$ and $y$ momentum}

We now must depth average the remaining momentum equations. The nonlinearity of these equations present difficulties in formulating a depth averaged theory. complicate the derivation, and in several places, it is necessary to take the depth average of products of terms. When necessary we approximate the required closure relation, for example as $\overline{\varphi f} \approx \bar{\varphi} \bar{f}$.

Consider first the equation for the motion of the solid phase. The left-hand side of the $x$ momentum equation (7) can be written

LHS $=\partial_{t} \varphi v^{x}+\partial_{x} \varphi v^{x}+\partial_{y} \varphi v^{x} v^{y}+\partial_{z} \varphi v^{x} v^{z}$.

Depth average and use boundary conditions to find

$$
\int_{b}^{h} \mathrm{LHSd} z=\partial_{t} \int_{b}^{h} \varphi v^{x} \mathrm{~d} z+\partial_{x} \int_{b}^{h} \varphi v^{x^{2}} \mathrm{~d} z+\partial_{y} \int_{b}^{h} \varphi v^{x} v^{y} \mathrm{~d} z
$$

A model for two phase debris flows

G. Córdoba et al.

Title Page

Abstract

Introduction

Conclusions

References

Tables

Figures

14

$>$ I

$\triangleleft$

Back

Close

Full Screen / Esc

Printer-friendly Version

Interactive Discussion 
Now depth average the right hand side of (7):

$$
\int_{b}^{h} \mathrm{RHSdz}=\underbrace{-\int_{b}^{h}\left(\epsilon \partial_{x} T^{s x x}+\epsilon \partial_{y} T^{s x y}+\partial_{z} T^{s x z}\right) d z}_{\text {(i) }}
$$

$\underbrace{-\frac{\rho^{f}}{\rho^{\mathrm{s}}} \int_{b}^{h} \epsilon \varphi \partial_{x} T^{\mathrm{f} x x} \mathrm{~d} z}_{\text {(ii) }}+\underbrace{\frac{D}{\rho^{\mathrm{s}}} \sqrt{\frac{L}{g}}\left(v_{x}-u_{x}\right)}_{\text {(iii) }}+\int_{b}^{h} \varphi g^{x} \mathrm{~d} z$.

In order to proceed, several assumptions are made:

- This equation governs the motion of the solid phase, and we assume the upper free surface for the mixture is a free surface for both of the individual phases.

- The drag term $\frac{D}{\rho^{s}}\left(v_{x}-u_{x}\right)$ is highly nonlinear and a correct depth average is all but impossible to calculate. We postulate that a experiments could fit an averaged phenomenological drag of a similar form.

- The earth pressure relation for the solid phase is employed. That is, the basal shear stresses are assumed to be proportional to the normal stress:

$T^{\mathrm{s} * z}=-\frac{v^{*}}{\|\boldsymbol{v}\|} \tan \left(\phi_{\mathrm{bed}}\right) T^{\mathrm{s} z z} \equiv \alpha_{* z} T^{\mathrm{s} z z}$

where * can be either $x$ or $y$, and the velocity ratio enforces that friction opposes motion inthe designated direction (Savage and Hutter, 1989; Patra et al., 2005) The $\alpha$ notation will provide a convenient shorthand that we use in other places.

NHESSD

3, 3789-3822, 2015

A model for two phase debris flows

G. Córdoba et al.

Title Page

Abstract

Introduction

Conclusions

References

Tables

Figures

14

$>$ I

4

Back

Close

Full Screen / Esc

Printer-friendly Version

Interactive Discussion 
Likewise the diagonal stresses are taken to be proportional to the normal solid stress

$T^{\mathrm{s} * *}=k_{\mathrm{ap}} T^{\mathrm{s} z z} \equiv \alpha_{* *} T^{\mathrm{s} z z}$.

NHESSD

3, 3789-3822, 2015

Finally, following Iverson and Denlinger (2001), $x y$ shear stresses are determined by a Coulomb relation

$T^{\mathrm{s} x y}=-\operatorname{sgn}\left(\partial_{y} v^{x}\right) \sin \left(\phi_{\mathrm{int}}\right) k_{\mathrm{ap}} T^{\mathrm{s} z z} \equiv \alpha_{x y} T^{\mathrm{s} z z}$,

where the sgn function ensures that friction opposes straining in the $(x, y)$ plane.

- For the fluid phase, the basal shear stresses are assumed to be proportinal to the square of the depth averaged velocities (Guo, 1995; Xu, 2004):

$T^{\mathrm{f} * z}=\rho^{\mathrm{f}} C_{f} u^{*}\|u\|$,

where $C_{f}$ is the friction coeficient. A physical approach for the friction coefficient is the Colebrook-White equation (Colebrook and White, 1937), which for rough channels can be approached as:

$\frac{1}{\sqrt{C_{\mathrm{f}}}}=-2 \log _{10}\left(\frac{k_{\mathrm{s}}}{14.8 R_{\mathrm{h}}}\right)$,

where $k_{\mathrm{s}}$ is the roughness of the channel and $R_{\mathrm{h}}$ is the hydraulic radii, which for shallow water problems can be approaced as the depth of the flow.

For pure fuids, the diagonal stresses and shear stress are zero.

A model for two phase debris flows

G. Córdoba et al.

Title Page

Abstract

Introduction

Conclusions

References

Tables

Figures

14

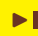

4

Back

Close

Full Screen / Esc

Printer-friendly Version

Interactive Discussion 
From Leibniz's rule and the stress computations above, we find

(ii) $=-\epsilon \frac{\rho^{\mathrm{f}}}{\rho^{\mathrm{s}}} \int_{b}^{h} \varphi \partial_{x} T^{\mathrm{f} x x} \mathrm{~d} z=$

NHESSD

$-\epsilon \frac{\rho^{f}}{\rho^{s}} \bar{\varphi}\left[\partial_{x}\left(\frac{\hat{h}^{2}}{2}\left(-g^{z}\right)\right)+\hat{h}\left(-g^{z}\right) \partial_{x} b\right]$

Now using the fluid and solid stress relation $\bar{T}^{\mathrm{szz}}=\left(1-\frac{\rho^{\mathrm{f}}}{\rho^{\mathrm{s}}}\right) \bar{\varphi} \bar{T}^{\mathrm{f} z z}$, term (i) is approx5 imated as:

(i) $=-\epsilon \int_{b}^{h} \partial_{x} \alpha_{x x} T^{\mathrm{s} z z} \mathrm{~d} z-\epsilon \int_{b}^{h} \partial_{y} \alpha_{x y} T^{\mathrm{s} z z} \mathrm{~d} z-\int_{b}^{h} \partial_{z} \alpha_{x z} T^{\mathrm{s} z z} \mathrm{~d} z$

$=-\epsilon\left[\partial_{x} \int_{b}^{h} \alpha_{x x} T^{\mathrm{s} z z} \mathrm{~d} z-\left.\alpha_{x x} T^{\mathrm{s} z z}\right|_{z=h} \partial_{x} h+\left.\alpha_{x x} T^{\mathrm{s} z z}\right|_{z=b} \partial_{x} b\right]-\epsilon\left[\partial_{y} \int_{b}^{h} \alpha_{x y} T^{\mathrm{s} z z} \mathrm{~d} z\right.$

$\left.-\left.\alpha_{x y} T^{\mathrm{s} z z}\right|_{z=h} \partial_{y} h+\left.\alpha_{x y} T^{\mathrm{s} z z}\right|_{z=b} \partial_{y} b\right]-\alpha_{x z}\left[\left.T^{\mathrm{s} z z}\right|_{z=h}-\left.T^{\mathrm{s} z z}\right|_{z=b}\right]$.

The upper free surface is stress free, so all terms involving $\left.T^{\mathrm{szz}}\right|_{z=h}$ vanish. The ex10 pression for (i) becomes

(i) $=-\epsilon\left(1-\frac{\rho^{f}}{\rho^{s}}\right) \partial_{x}\left(\hat{h} \alpha_{x x} \bar{\varphi} \bar{T}^{\mathrm{f} z z}\right)-\epsilon\left(1-\frac{\rho^{\mathrm{f}}}{\rho^{\mathrm{s}}}\right) \partial_{y}\left(\hat{h} \alpha_{x y} \bar{\varphi} \bar{T}^{\mathrm{f} z z}\right)$

$+\left(1-\frac{\rho^{f}}{\rho^{s}}\right)\left(-\epsilon \alpha_{x x} \partial_{x} b-\epsilon \alpha_{x y} \partial_{y} b+\alpha_{x z}\right)\left(-g^{z}\right) \hat{h} \bar{\varphi}$.

Note that the factor $\left(-g^{z}\right)$ originates in the evaluation and depth averaging of the fluid stress; in typical flows, this factor is positive.

A model for two phase debris flows

G. Córdoba et al.

\section{Title Page}

Abstract

Introduction

Conclusions

References

Tables

Figures

14

$>1$

4

Back

Close

Full Screen / Esc

Printer-friendly Version

Interactive Discussion

(c) (1) 
Combining all terms yields a solids $x$ momentum equation:

$\partial_{t}\left(\hat{h} \bar{\varphi} \overline{V^{x}}\right)+\partial_{x}\left(\hat{h} \bar{\varphi} \overline{V^{x} v^{x}}\right)+\partial_{y}\left(\hat{h} \bar{\varphi} \overline{V^{x} v^{y}}\right)=-\frac{\epsilon}{2}\left(1-\frac{\rho^{f}}{\rho^{s}}\right) \partial_{x}\left(\alpha_{x x} \hat{h}^{2} \bar{\varphi}\left(-g^{z}\right)\right)$

$-\frac{\epsilon}{2}\left(1-\frac{\rho^{f}}{\rho^{s}}\right) \partial_{y}\left(\alpha_{x y} \hat{h}^{2} \bar{\varphi}\left(-g^{z}\right)\right)+\left(1-\frac{\rho^{f}}{\rho^{s}}\right)\left(-\epsilon \alpha_{x x} \partial_{x} b-\epsilon \alpha_{x y} \partial_{y} b+\alpha_{x z}\right) \hat{h} \bar{\varphi}\left(-g^{z}\right)$

$-\frac{\epsilon}{2} \frac{\rho^{f}}{\rho^{s}} \bar{\varphi} \partial_{x}\left(\hat{h}^{2}\left(-g^{z}\right)\right)-\epsilon \frac{\rho^{f}}{\rho^{s}} \hat{h} \bar{\varphi}\left(-g^{z}\right) \partial_{x} b+\left(\frac{\bar{D}}{\rho^{s}}\right)\left(\overline{u^{x}}-\overline{v^{x}}\right)+\hat{h} \bar{\varphi} g^{x}$.

$5 \quad$ The $y$ solid momentum equation can be derived in a similar fashion.

The equation for the fluid motion presents fewer difficulties. The depth averaged $x$ momentum equation takes the form

$\partial_{t}\left(\hat{h} \overline{\varphi^{f}} \overline{u^{x}}\right)+\partial_{x}\left(\hat{h} \overline{u^{x}} \overline{\varphi^{f}} \overline{u^{x}}\right)+\partial_{y}\left(\hat{h} \overline{\varphi^{f}} \overline{u^{x} u^{y}}\right)$

$=-\frac{1}{2} \epsilon \partial_{x} \hat{h}^{2} \overline{\varphi^{\dagger}}\left(-g^{z}\right)-\left(\frac{\bar{D}}{\rho^{s}}\right)\left(\overline{u^{x}}-\overline{v^{x}}\right)+\hat{h} \overline{\varphi^{\dagger}} g^{x}+\overline{\varphi^{\dagger}} C_{f} u^{x}\|u\|$.

10 Where $\overline{\varphi^{f}}=1-\bar{\varphi}$. Again, the fluid $y$ momentum equation has a similar form. Note that if $\overline{\varphi^{f}} \rightarrow 1$ Eq. (25) becomes the typical shallow water approach of hydraulics (Chow, 1969) (Kowalski, 2008 describes how debris flows exhibit a shallow flow geometry as well).

This equation system is then solved using the finite volume method, whose solution provides results of the velocity field, flow depth and the volumetric concentration of solids at the center of the each finite volume computational grid. The bulk density can be calculated from:

$\rho=\rho^{\mathrm{s}} \varphi+\rho^{\mathrm{f}}(1-\varphi)$

NHESSD

3, 3789-3822, 2015

A model for two phase debris flows

G. Córdoba et al.

Title Page

Abstract

Introduction

Conclusions

References

Tables

Figures

14

- I

4

Back

Close

Full Screen / Esc

Printer-friendly Version Interactive Discussion 
Then, we obtain the dynamic pressure $p$ from:

$p=\frac{1}{2} \rho v^{2}$

NHESSD

3, 3789-3822, 2015

where $v$ is the speed of the flow. The use of the impacting dynamic pressure information on structures and living beings allows to estimate levels of damage, as in Valentine 5 (1998), Valentine et al. (2011), and Jones (2012), useful for vulnerability analysis.

The numerical solution of the above set of equations presents strong numerical sensitivity to small changes and Digital Elevation Model (DEM) errors. To solve the balance laws, we use the parallel, adaptive mesh, Godunov solver developed by Davis (1988) already implemented in Patra et al. (2005) and Pitman and Le (2005). The adaptive meshing is used as well, which allows to have very fine grids where indicators show high gradients, and coarser grids where low gradients are detected. The time step is adjusted from a Courant et al. (1928) like condition. The complexity of the equation system results in typical time steps of the order of $10^{-4}$. However, the maximum time step allowed was reduced from $10^{-1} \mathrm{~s}$ used within Titan2D to $10^{-3} \mathrm{~s}$ to ensure stability. As result, Titan2F become a computationally expensive tool.

Another source of numerical difficulties arise from the DEMs and the quality of that maps. The DEMS can have regions where elevations are not well defined, they can have crossed contour levels or even infinite holes. Abrupt terrain changes, both actual or DEM artifacts, cause computations of gradients and curvatures to become unstable. In order to avoid such a numerical problems patching and intelligent smoothing of the DEMs was needed.

There are four major differences between the present paper and Pitman and Le (2005):

1. In Pitman and Le (2005), mass and momentum conservation laws are derived for the solid material and for the phase averaged mixture of solid and fluid, whereas here the final model presents mass and momentum equations for both individual phases.

A model for two phase debris flows

G. Córdoba et al.

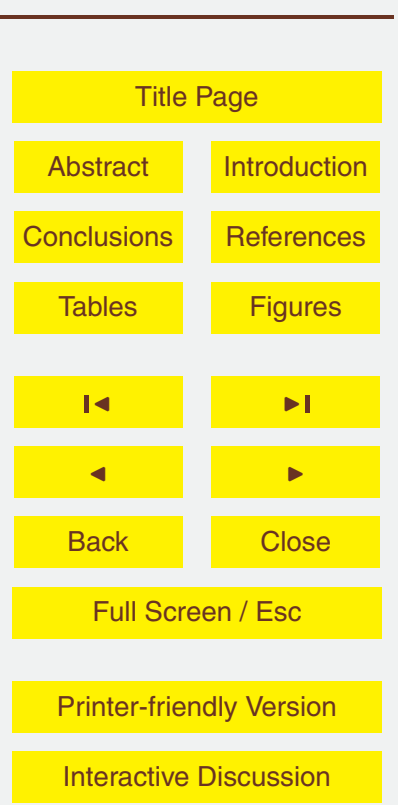

Interactive Discussion 
2. Any two phase model system must postulate several phenomenological functions, such as inter-phase drag coefficient. In the present derivation these functions are better adapted to geophysical flows whose fluid phase corresponds to water and the solid phase are rounded solid particle.

3. The volumetric particle concentration is not a fixed parameter, which in our approach is calculated for every time steep and grid point. When the particle concentration vanishes, the solid phase role in the equation system vanishes as well. In that way, the equation system becomes the typical hydraulic shallow water approach.

4. The only input parameters need by the program are the location of the pile of material, its volume and the volumetric solids concentration. The friction coefficients are no longer needed as input as they are authomaticaly adjusted accoding to the evolution of the volumetric fraction of solids across the grid and time. The bed and internal friction at set in such way that when the velometric fraction of solids tends to an assumed maximum packing concetration $(\varphi=0.65)$, both internal and bed frictions tends to the values used in that cases in Titan2D (0.35).

\section{Validation and verification}

In order to validate and verify the proposed approach, we did a series of tests using a one dimensional approach of the proposed equation system. First we test the consistency of the results verifying the expected symmetries. Then we used an exponentially decaying topography with and without obstacles (bumps). They show expected features like how the mathematical model can show a reflected wave when the bump was big enough or the flow splitting in a reflected dense part and bump overpass by a very dilute flow.

25 Verification of the accuracy of the code was done with analytical solutions of the Dam Break problem and with several experiment results. Among them, we check the 3807

\section{NHESSD}

3, 3789-3822, 2015

A model for two phase debris flows

G. Córdoba et al.

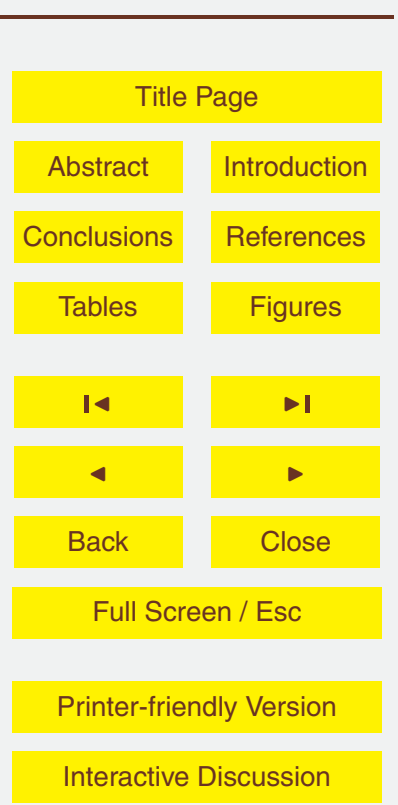


deposited pattern predicted by the program with the results shown by Liu (Liu, 1996). The prediction of the arrival time and the flow depth profile was compared with the experimental results shown by Iverson et al. (2010) from his recent work done on his large channel facility.

Analytical solutions for shallow water problems are scarce. Only one dimensional analytical approaches are available in the litereture, especially for the well known Dam Break problem (e.g. Dressler, 1954; Mangeney et al., 2000; Fernandez-Feira, 2006; Ancey et al., 2008; Wrachien and Mambretti, 2009). Unfortunately, analytical solutions for geo-mass flows are almost imposible to find due to the complexity of the the non10 linear partial differential equations (Pudasaini and Hutter, 2007). Such solutions can be obtained only in special cases like the similarity based solutions proposed by Savage and Hutter (Savage and Hutter, 1989) for dry avalenches. In our test we use the solution proposed by Fernandez-Feira (2006) for the Dam Break problem on an incline for pure water. In our program we assume $\varphi^{\mathrm{S}} \rightarrow 0$. Figure 1 shows a comparison of

the Two-Phase-Titan prediction with this analytical solution. At least for the one dimensional case, the program successfuly reproduces analytical solutions for different initial conditions down to very low paricle concentrations (less than $1 \%$ ).

Liu (1996) performed several experiments for geo-mass flows in an inclined channel. He modified the initial volume, the channel slope and the particle concentration to find the final size of the debris flows meassured by their resulting width and length. We reproduced experimental final width and length after the simulation reached the same time corresponding to the duration reported by Liu. Figure 2 shows the correspondense of the model with the experiments for (a) the width of the deposit and (b) the length. A Pearson correlation shows that $90 \%$ of the experimental data for the deposit lenght for the deposit width can be explained by the predictions of the program. This ilustrates the high accuracy of the program in predicting the deposit characteristics for different initial volumes and high initial solid concentrations.

\section{NHESSD}

3, 3789-3822, 2015

A model for two phase debris flows

G. Córdoba et al.
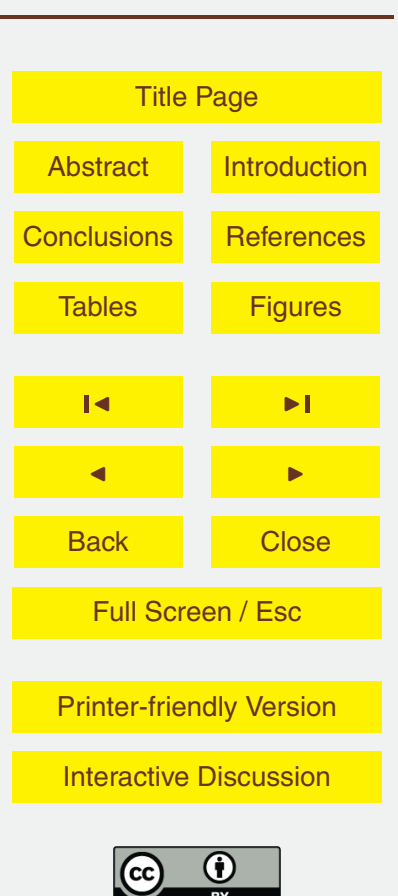
The experiments performed by Iverson and co-workers (Iverson et al., 2010) done on a $95 \mathrm{~m}$ long artificial channel was used to verify the accuracy of the predictions of the flow front arrival time and the temporal evolution of the flow depth. These flows were unsteady and nonuniform. Iverson et al. (2010) show time series data for several 5 meassured properties: flow thickness, pore pressure, basal normal stress and arrival time of the front. Raw data sent to us by Dr. Iverson were used to test the Two-PhaseTitan prediction concerning time evolution of the flow depth and arrival times at the check points located at 32 and $66 \mathrm{~m}$ distance from the lock. As shown in Figures 3 and 4 , the arrival time and the temporal evolution of the predicted depth fits very well within 10 the confidence interval of the experiments.

The range of concentrations that the program cope with, are from $\varphi_{s}=10^{-8}$ (almost pure water) to $\varphi_{s}=0.65$ (maximum packing concentration). Finally, as expected, the program predicts high particle concentrations at the front of the flow and low particle concentrations at the tail of the flow (at some cases, even near pure water concentrations, or $\varphi \rightarrow 0$ ), as can be seen in Fig. 5 where a longitudinal solids particle distribution predicted by Titan2F is shown. The predictions fits with Iverson et al. (2010) observation that the tail of the flow remains very watery. Using predicted concentration of solids, the density is assessed (Eq. 26) and together with the speed of the flow, the dynamic pressure distribution is calculated as well (Eq. 27). Figure 6 shows longitudinal and cross distributions of the dynamic pressures after $14 \mathrm{~s}$ simulation. As the flow velocity at lateral limits of the flow from the end of the channel are very low, the dynamic pressure shows to be low as well. Knowledge of the dymaic pressure information is of vital importance in risk analysis as structural damage and risk for human life can be assessed from it.

Verification with actual mud flows has been done as well, showing very good fit with field data. For example, Sheridan et al. (2011) shows that the Titan2F predictions are within $10 \%$ of the data shown by Procter et al. (2010) for the highly channeled mud flow at Ruapehu, New Zealand. In addition, the theory was tested against field data assessed by Williams et al. (2008) for the 2006 Vazcun creek lahar at Tungurahua

\section{NHESSD}

3, 3789-3822, 2015

\section{A model for two phase debris flows}

G. Córdoba et al.

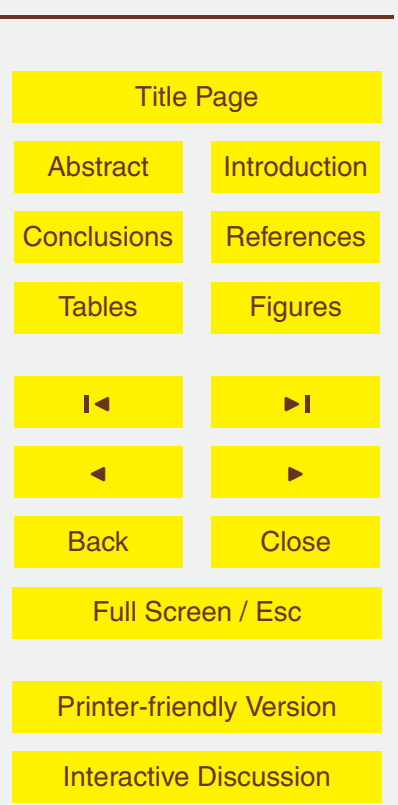


volcano, Ecuador, as shown by Cordoba et al. (2015), where Titan2F predictions about velocity are within $10 \%$ and within $15 \%$ for the meassured super-elevation.

\section{Conclusions}

In this paper we present a new computational two phase tool for lahar hazard assess5 computes space-time evolution of the particle concentration, flow depth, velocity field and dynamic pressure at each ponit of the computational grid.

The model is valid for two phase flows whose phases consist in solids and water. However, the phenomenological approach used for the interphase drag model assumes an average diameter of the solids, which mean individual boulders or particles cannot be tracked. In addition, the model is depth averaged, assuming thin layer and shadow water approaches. Thus, our model correctly predicts the dynamic of gravity driven flows providing the depth averaged values for the particle concentration, flow and phases velocities and flow depth in a three dimensional topography. In order to model other kind of geophysical mass flows, adjustments to the code must be done, for example pyroclastic flows can be modeled if the flow density of the fluid phase is appropriately addressed (eg. thermocoupled air density using ideal gas law and an additional equation for temperature).

The proposed mathematical approach allows to study the whole range of flow be20 haviour. Regions with almost pure fluid to regions of friction dominated flows are correctly described by the algorithm. Using this information, dynamic pressure is deduced, which becomes a very useful tool for risk assessment.

The highly non-linear coupled equation system makes the time step very small. The use of this neew tool on natural terrains or detailed Digital Elevetion Models (DEMs) 25 requires higher computational power than the one provided for home PCs. The use of a high velocity Work Station with multiple cores is adviced.

\section{NHESSD}

3, 3789-3822, 2015

A model for two phase debris flows

G. Córdoba et al.

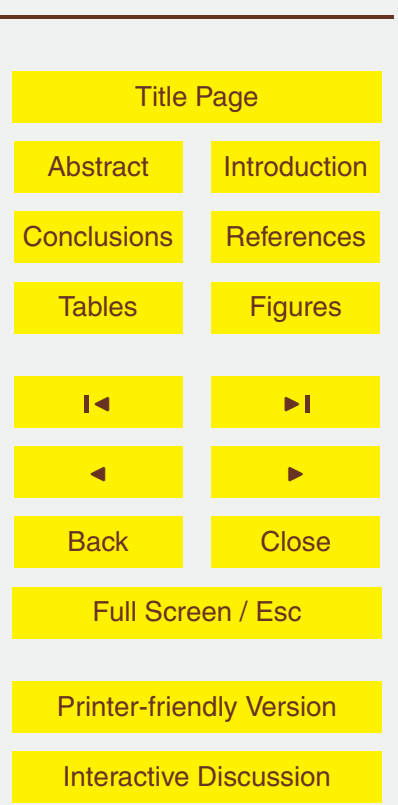

Interactive Discussion 
Important processes that are not addressed by this tool include the effect of turbulence, incorporation of solid material from the bed of the channel, and incorporation of water into the flow from existing water bodies. Nevertheless, this two-phase flow is an important step forward in forming an aceptable computational model for simulat5 ing a hazardous natural phenomena. Currently, we are applying this tool for real lahar hazard assessments like in Cordoba et al. (2015).

\section{The Supplement related to this article is available online at doi:10.5194/nhessd-3-3789-2015-supplement.}

Author contributions. Gustavo Córdoba, Michael Sheridan and Bruce Pitman developed the 10 mathematical approach of the model. Gustavo Córdoba did the coding.

Acknowledgements. The authors wish to thank the economic support provided by the National Science Foundation Grant EAR 711497 aimed to the developing of Two-Phase-Titan. We also want to thanks Ramona Stefanescu, Abani Patra, Dinesh Kumar and Keith Dalbey from University of Buffalo for the useful discussions about this development, and to Dr. Richard Iverson from USGS who sent us the raw data of his experiments. The Universidad de Nariño, Colombia, allowed the mobility of Cordoba to assume the post-doctoral possition at the University of Buffalo (2008-2010) where the mathematical approach and coding of the beta version was developed, and later gave him the necessary dedication time for this research.

\section{References}

Ancey, C.: Plasticity and geophysical flows: a review, J. Non-Newton Fluid, 142, 4-35, 2006. 3792

Ancey, C., Iverson, R., Rentschler, M., and Denlinger, R.: An exact solution for ideal dam-break floods on steep slopes, Water Resour. Res., 44, W01430, doi:10.1029/2007WR006353, 2008. 3808

\section{NHESSD}

3, 3789-3822, 2015

A model for two phase debris flows

G. Córdoba et al.

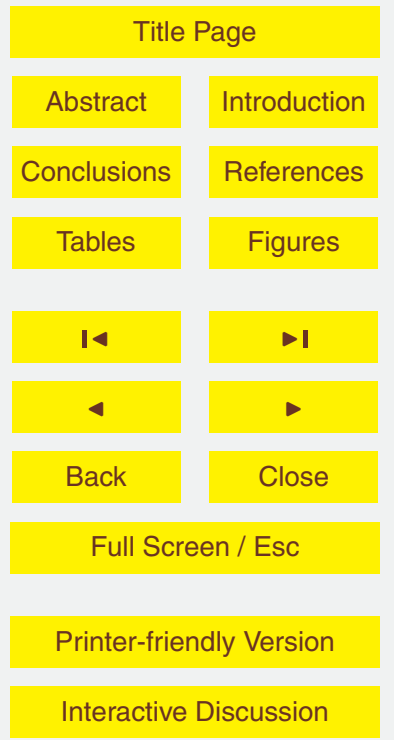


Anderson, T. B. and Jackson, R.: A fluid mechanical description of fluidized beds: equations of motion, Ind. Eng. Chem. Fund., 6, 527-539, 1967. 3794

Balmforth, N. J. and Craster, R. V.: A consistent thin-layer theory for Bingham plastics, J. NonNewton Fluid, 84, 65-81, 1999. 3792

5 Bedford, A. and Drumheller, D. S.: Recent advances: theories of immicible and structured mixtures, Int. J. Eng. Sci, 21, 863-960, 1983. 3792

$\mathrm{Xu}, \mathrm{K}$. : The gas-kinetic scheme for shallow water equations, Journal of Hydrodynamics, Proceedings of the Conference of Global Chinese Scholars on Hydrodynamics, 73-76, Shangai, China, 11-14 July, 2006. 3803

10 Chow, V.: Open Channel Hydraulics, McGraw Hill, New York, 19693805

Colebrook, C. and White, C.: Experiments with fluid friction in Roughened pipes, P. R. Soc. London, 161, 367-381, 1937. 3803

U.S.-Geodynamics-Committee: Mount Rainier: Active Cascade Volcano, National Academic Press, Washington, D.C., 1994. 3790

Córdoba, G., Villarosa, G., Sheridan, M. F., Viramonte, J. G., Beigt, D., and Salmuni, G.: Secondary lahar hazard assessment for Villa la Angostura, Argentina, using Two-Phase-Titan modelling code during 2011 Cordón Caulle eruption, Nat. Hazards Earth Syst. Sci., 15, 757766, doi:10.5194/nhess-15-757-2015, 2015. 3810, 3811

Courant, R., Friedrichs, K., and Lewy, H.: On the partial difference equations of mathematical physics, Math. Ann., 100, 32-74, 1928. 3806

Coussot, P.: Mudflow Rheology and Dynamics, IAHR Monograph Series, Balkema, 1997. 3792

Dartevelle, S.: Numerical modeling of geophysical granular flows: 1. A comprehensive approach to granular rheologies and geophysical multiphase flows, G-cubed-GeochemistryGeophysics-Geosystems, 5, Q08003, doi:10.1029/2003GC000636, 2004. 3792

Davis, S. F.: Simplified second order Godunov-type methods, SIAM J. Sci. Stat. Comp., 9, 445473, 1988. 3806

Dobran, F.: Theory of structured multiphase mixtures, Lect. Notes Phys., Volume 372, Springer, Berlin, Deutschland, 1991. 3792, 3793

Dobran, F.: Volcanic Processes: Mechanisms in Material Transport, Kluwer Academic, NY, 2001. 3794

Dobran, F., Neri, A., and Macedonio, G.: Numerical Simulation of collapsing volcanic columns, J. Geophys. Res., 98, 4231-4259, 1993. 3794 
Dressler, R. F.: Comparison of theories and experiments for hydraulic dam break waves, Proc. Int. Assoc. of Scientific Hydrology Assemblee Generale, 38, 319-328, 1954. 3808

Ergun, S.: Fluid flow through packed columns, Chem. Eng. Prog., 49, 89-94, 1952. 3794

Fan, L. and Zhu, C.: Principles os Gas-Solid Flows, Cambridge CB22RU, Cambridge, 1998. 3794

Fernandez-Feira, R.: Dam-break flow for arbitrary slopes on the bottom, J. Eng. Math., 54, 319-331, 2006. 3808

Gidaspow, D.: Multiphase Flow and Fluidization, Academic Press, New York, 1994. 3794

Hutter, K., Wang, Y., and Pudasaini, S. P.: The Savage-Hutter Avalanche Model: How far can it be pushed?, Preprint, NI03072-GPF, Isaac Newton Institute for Mathematical Sciences, Cambridge, UK, 2003. 3792

Gray, J. M., Wieland, M., and Hutter, K.: Gravity-driven free surface flow of granular avalanches over complex basal terrain, P. Roy. Soc. Lond. A, 455, 1841-1874, 1999. 3791

Guo, Z.: Velocity-depth coupling in shallow-water flows, J. Hydrol. Eng., 121, 717-724, 1995. $15 \quad 3803$

Iverson, R. M.: The physics of debris flows, Rev. Geophys., 35, 245-296, 1997. 3792

Iverson, R. M. and Denlinger, R. P.: Flow of variably fluidized granular material across threedimensional terrain 1: Coulomb mixture theory, J. Geophys. Res., 6, 537-552, 2001. 3792, 3795, 3799, 3803

20 Iverson, R. M., Logan, M., LaHusen, R. G., and Berti, M.: The perfect debris flow? Agregated results from 28 large-scale experiments, J. Geophys. Res., 115, F03005, doi:10,1029/2009FJ001514, 2010. 3808, 3809, 3819, 3820, 3821

Jackson, R.: The Dynamics of Fluidized Particles, Cambridge Monographs on Mechanics, Cambridge University Press, Cambridge, UK, 2000. 3792, 3793, 3794

Jones, N.: Damage of plates due to impact, dynamic pressure and explosive loads, Lat. Am. J. Solids Stru., 10, 767-780, 2012. 3806

Khan, A. R. and Richardson, J. F.: Fluid-particle interactions and flow characteristics of fluidized and settling beds ans settling suspensions of spherical particles, Chem. Eng. Commun., 78, 111-130, 1989. 3795

30 Kowalski, J.: Two-Phase Modeling of Debris Flows, PhD thesis, Eidgenossische Technische Hochschule (ETH), Zurich, Switzerland, 135 pp., 2008. 3805

Legros, F.: The mobility of long runout landslides, Eng. Geol., 63, 301-331, 2002. 3791

\section{NHESSD}

3, 3789-3822, 2015

\section{A model for two phase debris flows}

G. Córdoba et al.

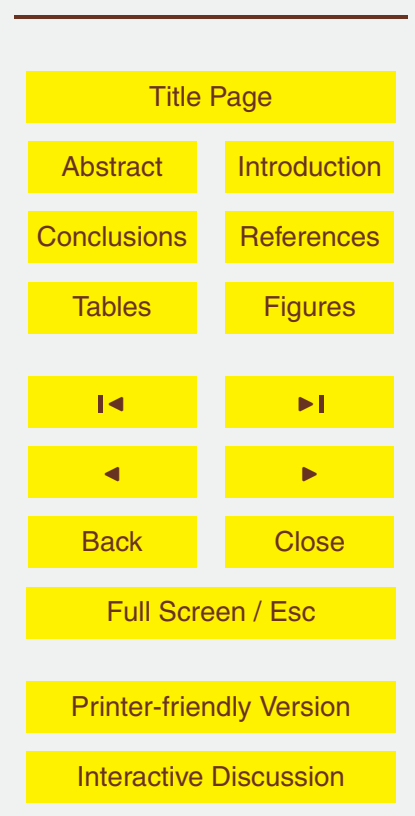

Interactive Discussion 
Liu, X.: Size of a debris flow deposition: model experiment approach, Environ Geol., 28, 70-77, 1996. 3808, 3818

Mangeney, A., Heinrich, P., and Roche, R.: Analytical solution for testing debris avalanche numerical models, Pure Appl. Geophys., 157, 1081-1096, 2000. 3808

5 Mazzei, L. and Lettieri, P.: A drag force closure for uniformly dispersed fluidized suspensions, Chem. Eng. Sci., 62, 6129-6142, 2007. 3794, 3795

Mei, K., Liu, F., and Yuhi, M.: Mud flow - slow and fast, Geomorph. Fluid Mech., 22, 548-577, 2001. 3792

Meruane, C., Tamburrino, A., and Roche, O.: On the role of the ambient fluid on gravitational granular flow dynamics, J. Fluid Mech., 648, 381-404, 2010. 3792

Neri, A., Ongaro, T. E., Macedonio, G., and Gidaspow, D.: Multiparticle simulation of collapsing volcanic columns and pyroclastic flows, J. Geophys. Res., 108, 508-531, 2003. 3794

Neri, A., Ongaro, T. E., Menconi, G., Vitturu, M., Cavazzoni, C., Erbacci, G., and Baxter, P.: 4D simulation of explosive eruption dynamics at Vesuvius, Geophys. Res. Lett., 34, 1-7, 2007. 3794

Panneerselvan, R., Savithri, S., and Surender, G. D.: CFD based investigations on hydrodynamics and energy dissipation due to solid motion in liquid fluidised bed, Chem. Eng. J., 132, 159-171, 2007. 3794

Patra, A., Bauer, C., Nichita, C., Pitman, E., Sheridan, M., Bursik, M., Rupp, B., Webber, A., Stinton, A., Namikawa, L., and Renschler, C.: Parallel adaptive numerical simulation of dry avalanches over natural terrain, J. Volcanol. Geoth. Res., 139, 1-21, 2005. 3791, 3802, 3806

Pelanti, M., Bouchut, F., and Mangeney, A.: A Roe-type scheme for two-phase shallow granular flows over variable topography, Math. Model. Numeric. Analy., 42, 851-885, 2008. 3792

Pistolesi, M., Cioni, R., Rosi, M., Cashman, K. V., Rossotti, A., and Aguilera, E.: Evidence for lahar-triggering mechanisms in complex stratigraphic sequences: the post-twelfth century eruptive activity of Cotopaxi Volcano, Ecuador, B. Volcanol., 75, 698, , 2013. 3791

Pitman, E. B. and Le, L.: A two-fluid model for avalanche and debris flows, Philos. T. R. Soc., 363, 1573-1601, 2005. 3792, 3793, 3799, 3806

Procter, J. N., Cronin, S. J., Fuller, I. C., Sheridan, M., Neall, V. E., and Keys, H.: Lahar hazard assessment using Titan2D for an alluvial fan with rapidly changing geomorphology: Whangaehu River, Mt. Ruapehu, Geomorphology, 116, 162-174, 2010. 3791, 3809

Pudasaini, S. P. and Hutter, K.: Rapid shear flows of dry granular material down curved and twisted channels, J. Fluid Mech., 495, 193-208, 2003. 3791

\section{NHESSD}

3, 3789-3822, 2015

\section{A model for two phase debris flows}

G. Córdoba et al.

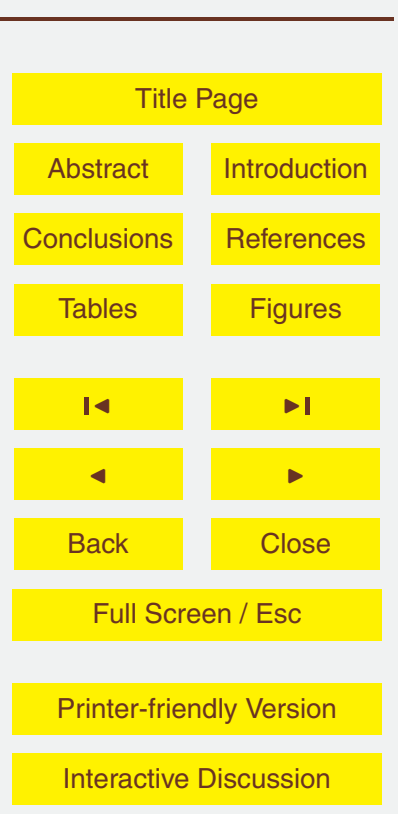

Interactive Discussion 
Pudasaini, S. P. and Hutter, K.: Avalanche Dynamics, Springer-Verlag, Berlin, 2007. 3792, 3808

Rankine, W. J. M.: On the stability of loose earth, Philos. T. R. Soc. Lond., 147, 9-27, 1957. 3798

Savage, S. B. and Hutter, K.: The motion of a finite mass of granular material down a rough incline, J. Fluid Mech., 199, 177-215, 1989. 3791, 3799, 3802, 3808

Sheridan, M.: Emplacement of pyroclastic flows: a review, Geol. S. Am S., 180, 125-136, 1979. 3790

Sheridan, M.: Pyroclastic block flow from the September 1976, eruption of La Soufrière Volcano, Guadaloupe, Bull. Volcanol., 43-2, 397-402, 1980.

10 Sheridan, M. and Malin, M.: Application of computer-assisted mapping to volcanic hazard evaluation of surge eruptions: Vulcano, Lipari and Vesuvius, J. Volcanol. Geoth. Res., 17, 187202, 1983.

Sheridan, M. F., Bonnard, C., Carreno, R., Siebe, C., Strauch, W., Navarro, M., Calero, J. C., and Trujillo, N. B.: Rockfall/avalanche and breakout flow of Casita Volcano, Nicaragua, Landslide

15 News, 12, 2-4, 1999. 3791

Sheridan, M. F., Stinton, A. J., Patra, A. K., Bauer, A. C., Nichita, C. C., and Pitman, E. B.: Evaluating TITAN2D mass-flow model using the 1963 Little Tahoma Peak avalanches, Mount Rainier, Washington., J. Volcanol. Geoth. Res., 139, 89-102, 2005. 3792

Sheridan, M., Córdoba, G., Pitman, E., Cronin, S., and Procter, J.: Application of a wide-ranging two-phase Debris Flow Model to the 2007 Crater Lake break-out lahar at Mt. Ruapehu, New Zealand, American Geophysical Union Fall Meeting, San Francisco (CA), 5-9 December 2011, abstract V53E-2691, 2011. 3809

Terzaghi, K.: The shearing resistance of saturated soils and the angle between planes of shear, Proc. 1st Int. Conf. Soil Mech., 22-26 June 1936, Cambridge, Mass., 54-56, 1936. 3798

The-Committee-on-Natural-Disasters: The Eruption of Nevado del Ruiz Volcano, Colombia, South America, November 13, 1985, Natural Disaster Studies, V4, National Academic Press, Washington, D.C., 1991. 3790

Tilling, R. I.: Volcanoes, U.S. Geological Survey, US Government Peinting Office, Washington, D.C., 1996. 3790

30 Valentine, G.: Damage to structures by pyroclastic flows and surges, inferred from nuclear weapons effects, JVGR, 87, 117-140, 1998. 3806

Valentine, G. and Wohletz, K.: Numerical models of plinian eruptions columns and pyroclastic flows, J. Geophys. Res., 94, 1867-1887, 1989. 3792, 3794

\section{NHESSD}

3, 3789-3822, 2015

\section{A model for two phase debris flows}

G. Córdoba et al.

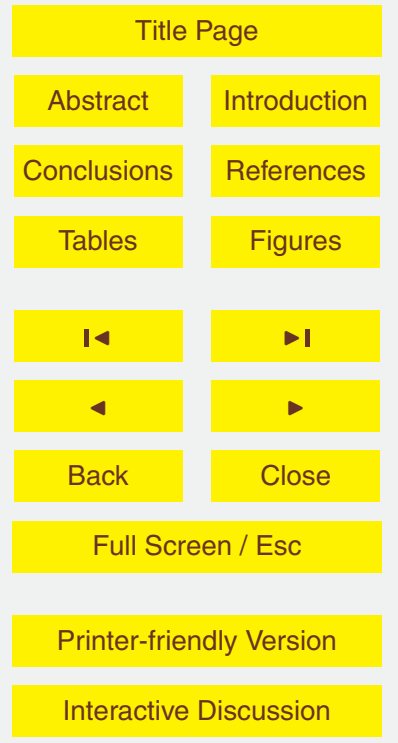


Valentine, G., Doronzo, D., Dellino, P., and Tullio, M.: Effects of volcano profile on dilute pyroclastic density currents: numerical simulations, Geology, 39, 947-950, 2011. 3806

Wallis, G. B.: One-Dimensional Two-Phase Flow, McGraw Hill, NY, 1969. 3794

Williams, R., Stinton, A. J., and Sheridan, M. F.: Evaluation of the Titan2D two-phase flow model 5 using an actual event: case study of the 2005 Vazcún Valley Lahar, J. Volcanol. Geoth. Res., 177, 760-766, 2008. 3809

Wrachien, D. and Mambretti, S.: Dam-Break Problems, Solutions and Case Studies, WITpress, Southampton, UK, 2009. 3808

\section{NHESSD}

3, 3789-3822, 2015

A model for two phase debris flows

G. Córdoba et al.

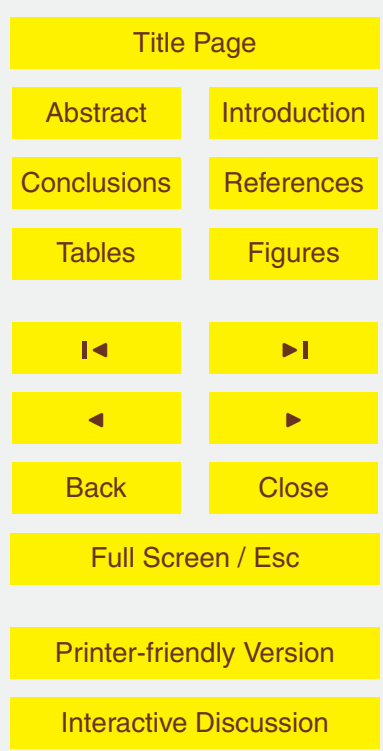




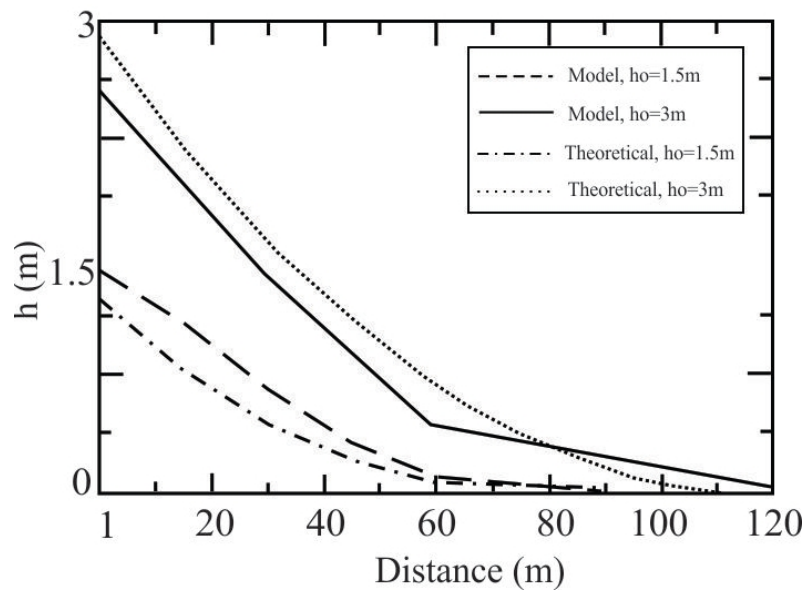

\section{NHESSD}

3, 3789-3822, 2015

A model for two phase debris flows

G. Córdoba et al.

\section{Title Page}

\begin{tabular}{|c|c|}
\hline Abstract & Introduction \\
\hline Conclusions & References \\
\hline Tables & Figures \\
\hline $\mathbf{1 4}$ & \\
\hline & \\
\hline Back & Close \\
\hline
\end{tabular}

Full Screen / Esc shows the result of the theoretical solution and thet results from the numerical model for two initial conditions $\left(h_{o}=3 \mathrm{~m}\right.$ and $\left.h_{o}=1.5 \mathrm{~m}\right)$.

Interactive Discussion 

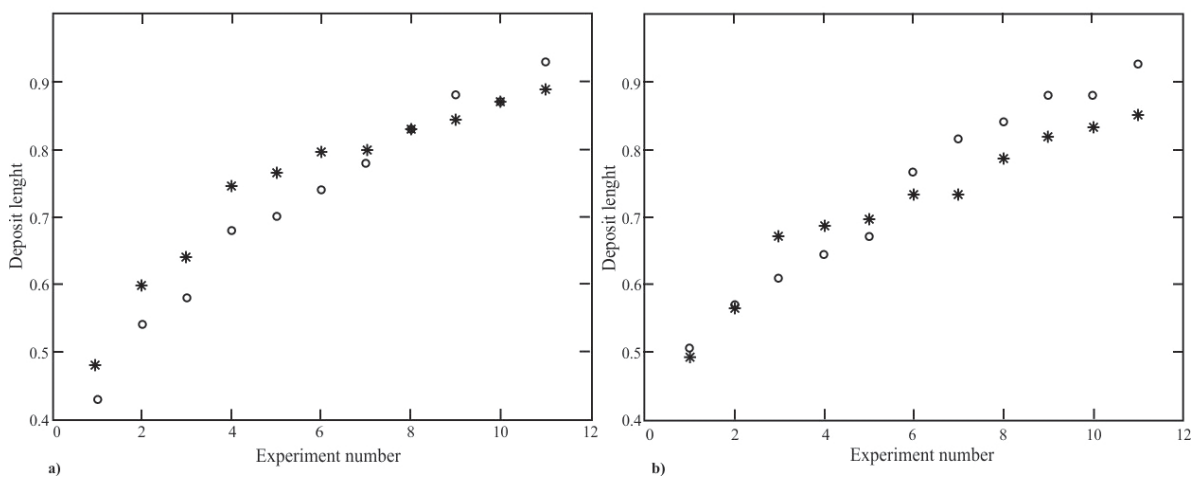

Figure 2. Graphic comparison of the predictions of Two-Phase-Titan for the experiments performed by Liu (1996). The results for several initial volumes compare (a) the width of the deposit and (b) the length of the deposit. The circles show data from the experiments, and the asterisks the predictions of Titan2F.

\section{NHESSD}

3, 3789-3822, 2015

A model for two phase debris flows

G. Córdoba et al.

\section{Title Page}

\begin{tabular}{|c|c|}
\hline Abstract & Introduction \\
\hline Conclusions & References \\
\hline Tables & Figures \\
\hline & \\
\hline & \\
\hline & \\
\hline Back & Close \\
\hline
\end{tabular}

Full Screen / Esc

Printer-friendly Version

Interactive Discussion 


\section{NHESSD}

3, 3789-3822, 2015

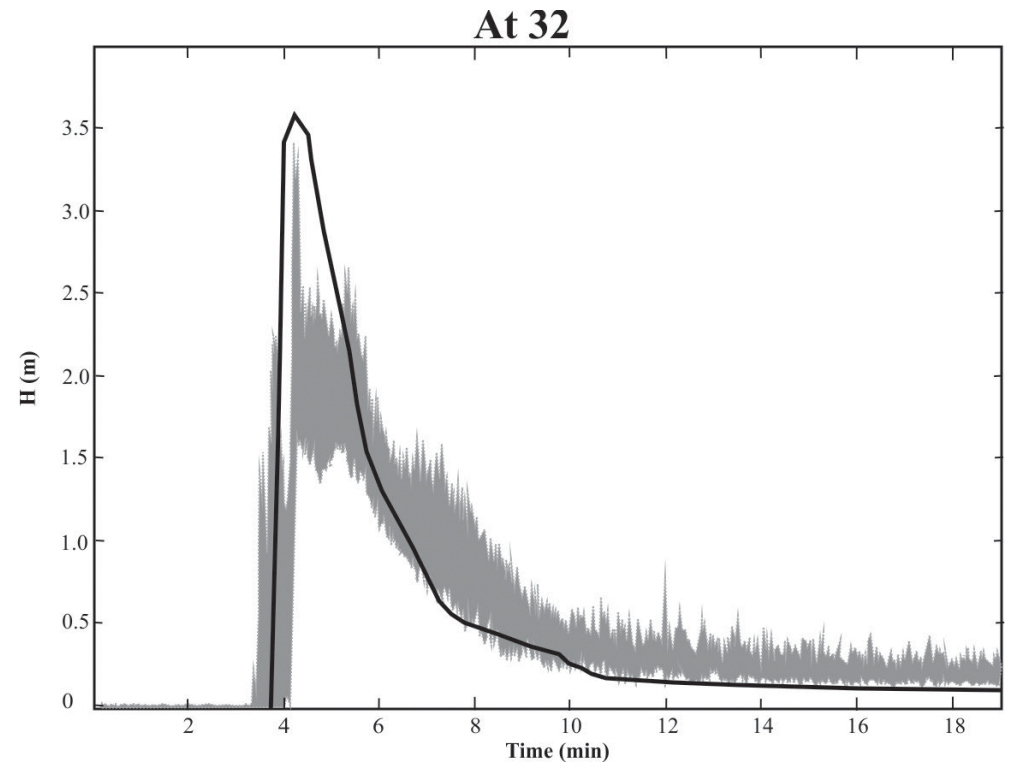

Figure 3. Verification of the accuracy of the Two-Phase-Titan predictions for the time evolution of the flow depth and arrival of the front at $32 \mathrm{~m}$ distace from the lock. The dotted lines represent the confidence interval of the experiments performed by Iverson and co-workers (Iverson et al., 2010).

\section{A model for two phase debris flows \\ G. Córdoba et al. \\ Title Page

\begin{tabular}{|c|c|}
\hline Abstract & Introduction \\
\hline Conclusions & References \\
\hline Tables & Figures \\
\hline $\mathbf{1}$ & \\
\hline 4 & -1 \\
\hline Back & Close \\
\hline
\end{tabular}

Full Screen / Esc

Printer-friendly Version

Interactive Discussion

(c) (1) 


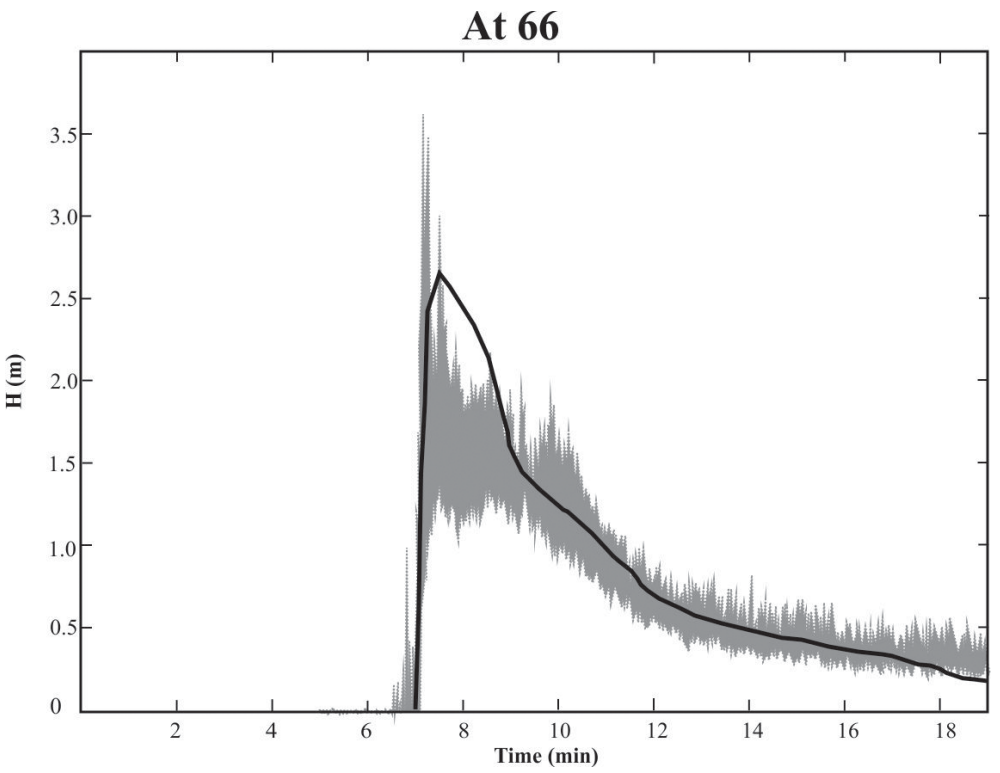

\section{NHESSD}

3, 3789-3822, 2015

\section{A model for two} phase debris flows

G. Córdoba et al.

\section{Title Page}

\begin{tabular}{|c|c|}
\hline Abstract & Introduction \\
\hline Conclusions & References \\
\hline Tables & Figures \\
\hline 14 & \\
\hline & \\
\hline Back & Close \\
\hline
\end{tabular}

Full Screen / Esc

Figure 4. Verification of the accuracy of the Two-Phase-Titan predictions for the time evolution of the flow depth and arrival of the front at $66 \mathrm{~m}$ distace from the lock. The dotted lines represent the confidence interval of the experiments performed by Iverson and co-workers (Iverson et al., 2010).

Interactive Discussion 


\section{NHESSD}

3, 3789-3822, 2015

\section{A model for two} phase debris flows

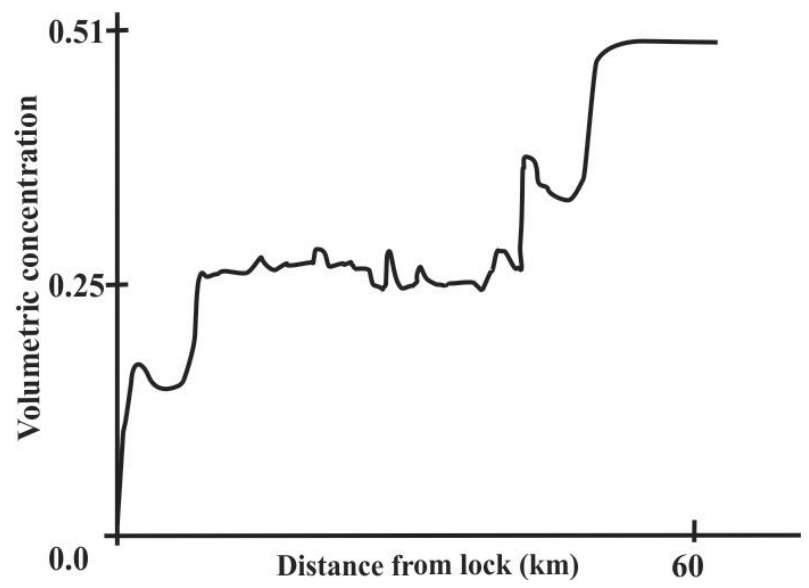

G. Córdoba et al.

\section{Title Page}

\begin{tabular}{|c|c|}
\hline Abstract & Introduction \\
\hline Conclusions & References \\
\hline Tables & Figures \\
\hline $\mathbf{1 4}$ & \\
\hline & \\
\hline Back & Close \\
\hline
\end{tabular}

Full Screen / Esc becomes very concentrated, as observed by Iverson et al. (2010).

Printer-friendly Version

Interactive Discussion 


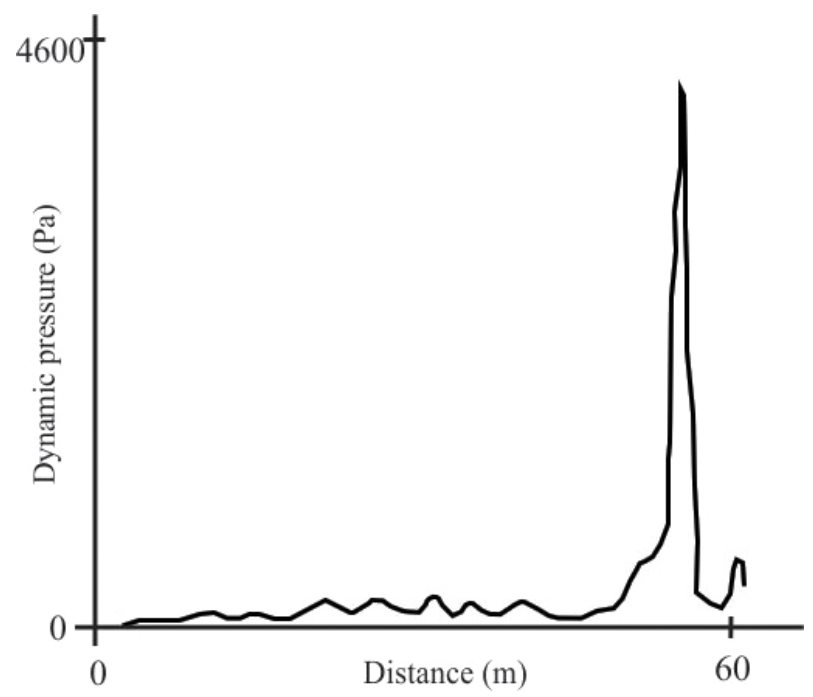

NHESSD

3, 3789-3822, 2015

A model for two phase debris flows

G. Córdoba et al.

Title Page

\begin{tabular}{c|c|}
\hline Abstract & Introduction \\
\hline Conclusions & References \\
\hline Tables & Figures \\
\hline 14 & -1 \\
\hline & \\
\hline Back & Close \\
\hline
\end{tabular}

Full Screen / Esc

Figure 6. Longitudinal distribution of the predicted dynamic pressure at $14 \mathrm{~s}$. The peak overpressure occurs just at the end of the inclined part of the channel.
Printer-friendly Version

Interactive Discussion 